\title{
Expansive cervical laminoplasties - Observations on comparative changes in spinous process lengths following longitudinal laminal divisions using autogenous bone or hydroxyapatite spacers
}

\author{
Kazuto Hoshi, Takahide Kurokawa, Kozo Nakamura, Yuichi Hoshino, Kazuo Saita and Kota Miyoshi \\ Department of Orthopedic Surgery, Faculty of Medicine, The University of Tokyo, 7-3-1 Hongo, Bunkyo-ku, Tokyo, \\ 113, Japan
}

Expansive laminoplasty is devised to preserve the posterior structures, including the original length of the spinous process which anchors the nucheal muscles, in order to prevent the postoperative development of instability and cervical kyphosis due to structural loss and poor tone of the nucheal muscles, which can result in late neurological regression after laminectomy for cervical myelopathy.

We retrospectively compared the length of the spinous process at the time of follow-up with that within 3 months postoperatively using CT images. The shortening was observed in $80 \%$ of 60 spinous processes in 13 patients, where a hydroxyapatite (HA) block was used as a spacer placed between the two sides of the split spinous process. The incidence was $9 \%$ of 22 spinous processes in six patients where auto bone graft (ABG) was used as a spacer, and the difference was significant $(P<0.01$, Chi-square test $)$.

Although the usage of $\mathrm{HA}$ has the advantage of being less invasive than $\mathrm{ABG}$, it may jeopardize the biomechanical function of nucheal muscles due to reduction in the original length of the spinous process.

Keywords: expansive cervical laminoplasty; spinous process; hydroxyapatite

\section{Introduction}

Late neurological deterioration after laminectomy for cervical myelopathy has been reported to be $18 \%{ }^{1}$ or $60 \%,{ }^{2}$ and the cause was thought to be the development of instability and cervical kyphosis due to structural loss and poor tone of the nucheal muscles. ${ }^{1,2}$

In order to prevent the postoperative development of abnormal alignment, we devised expansive laminoplasty, where the posterior structure is preserved to the greatest degree possible. ${ }^{3}$ We have reported good results with this procedure; improvement of motor function in 48 patients out of 56 with cervical myelopathy, and maintenance in 45 patients $;{ }^{4}$ and no postoperative neurological deterioration at the 4 year follow-up in seven patients with cervical spondylotic myelopathy associated with the athetoid type cerebral palsy.

In this procedure, an auto bone graft $(A B G)$ is inserted as a spacer between the two sides of the split spinous processes which are displaced aside laterally (Figure 1). ${ }^{3}$ Recently, in order to decrease the operation time and bleeding during the operation and to avoid postoperative pain around the donor site of the graft, ${ }^{6,7}$ we began to use the hydroxyapatite

Correspondence: K Hoshi
(HA) spacer instead of ABG. However, shortening of the spinous process as noted at follow-up was noted in some patients with HA. ${ }^{8,9}$ This phenomenon may jeopardize the concept of this procedure in a biomechanical aspect.

The purpose of this study was to determine the incidence of the shortening of the spinous process in patients with an expansive laminoplasty.

\section{Patients and methods}

We have retrospectively reviewed 19 patients, 13 of whom had HA and six ABG, operated on between 1985 and 1992 in the University of Tokyo Hospital by expansive cervical laminoplasty devised by Kurokawa. ${ }^{3}$

The operative technique of this procedure is as follows: Through a midline longitudinal incision only one side of the paravertebral muscles is separated from the nucheal ligament to preserve the tone of this ligament, and the ligament is then separated from the spinous processes. Deep nucheal muscles are retracted from their site of origin to expose the laminae and the spinous processes (Figure 1 (1)). The latter are carefully split vertically along the midline using a small round cutting bur. Two bony gutters are made just medial to the facet joint and pedicle with a high speed bur (Figure 1 (2)). The spinous processes and 


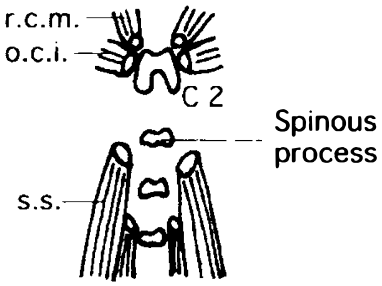

(1)

(2)
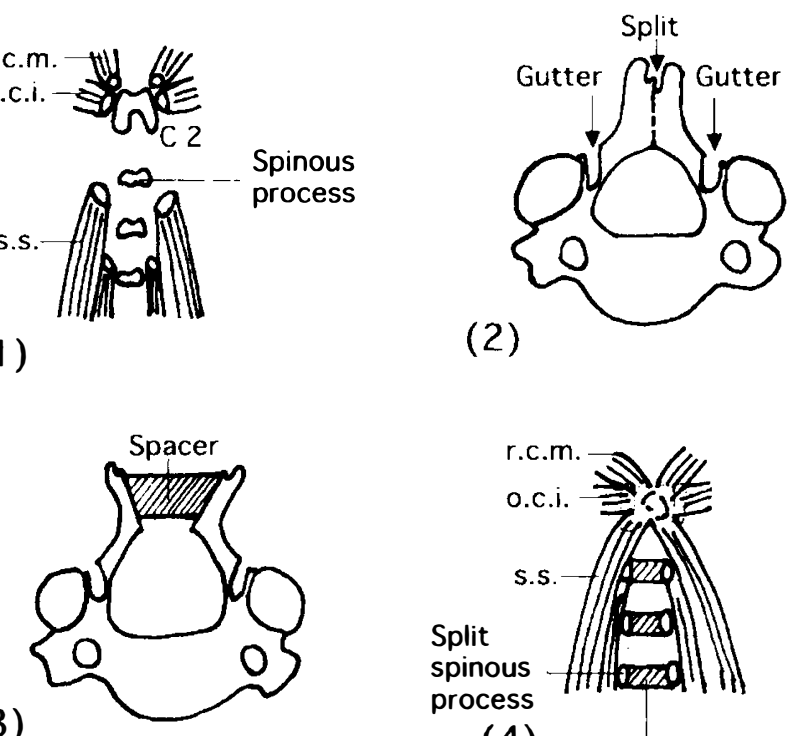

(3)

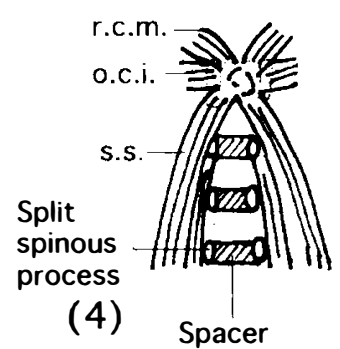

Figure 1 Operative procedures of expansive laminoplasty. (1) Deep nucheal muscles are removed from their place of origin, and the lamina and the spinous process are exposed. (2) The spinous process is split vertically along the midline using a small round cutting bur. Two bony gutters are made just medial to the facet joint and pedicle with a high speed bur. (3) The spinous process and lamina are pushed aside laterally, as if opening a double-leafed hinged door, and a spacer is put between the two sides of the split process. (4) Muscles removed from $\mathrm{C} 2$ are sutured again on the original site, and their tension is restored. r.c.m.: musculus rectus capitis posterior minor. o.c.i.: Musculus obliquus capitis inferior. s.s.: Musculus semispinalis cervicis laminae are displaced laterally, as if opening a doubleleafed hinged door and spacers, either ABG blocks or HA spacers, are placed between the two sides of the split processes (Figure 1 (3)). Finally, the deep nucheal muscles separated from the $\mathrm{C} 2$ spinous process are again sutured onto the original site in order to restore their tension (Figure 1 (4)), and the wound is closed.

Ten patients who had cervical spondylotic myelopathy (CS) and nine with myelopathy due to ossification of the posterior longitudinal ligament (OPLL) were included in this review. The age of the HA patients ranged 44 to 77 years (average, 59 years) and that of the ABG 52 to 68 years (average, 62 years). The HA spacer used was Boneceram-P (Sumitomo Cement Co., Ltd.) or Bonefil (Mitsubishi Material Co., Ltd.). Standards of the former are: $40 \%$ average porosity; trapezoid-shape with the $12 \mathrm{~mm}$ long upper bar, $18 \mathrm{~mm}$ lower bar, $8.5 \mathrm{~mm}$ width and $5 \mathrm{~mm}$ height. Standards of the latter: $60 \%$ average porosity; trapezoid-shape with the $12 \mathrm{~mm}$ long upper bar, $15 \mathrm{~mm}$ lower bar, $7 \mathrm{~mm}$ width, and $8 \mathrm{~mm}$ height.

We measured the length of the spinous process under the bone-augmented condition on $66 \%$ scaleddown CT images, using a GECT 9000 (Yokokawa Co., Japan). Two images taken less than 3 months and more than 6 months after surgery at nearly the same plane were compared and divided into three categories, short, long and no change: short, the latter with more than $3 \mathrm{~mm}$ shorter in length; long, being longer than $3 \mathrm{~mm}$; no change, a difference within $3 \mathrm{~mm}$.

Table 1 Summary of patient characteristics

\begin{tabular}{|c|c|c|c|c|c|c|c|c|c|c|c|c|}
\hline \multirow[b]{2}{*}{ Patient } & \multirow{2}{*}{$\begin{array}{c}\text { First } \\
C T \\
\text { (weeks) }\end{array}$} & \multirow{2}{*}{$\begin{array}{c}\text { Second } \\
C T \\
\text { (months) }\end{array}$} & \multirow{2}{*}{\multicolumn{2}{|c|}{$\begin{array}{c}\text { Age at } \\
\text { surgery } \\
\text { (years) }\end{array}$}} & \multirow[b]{2}{*}{ Disease } & \multirow[b]{2}{*}{$C 2$} & \multirow[b]{2}{*}{ C3 } & \multicolumn{3}{|c|}{ Levels of the spine } & \multirow[b]{2}{*}{$C 7$} & \multirow[b]{2}{*}{$T 1$} \\
\hline & & & & & & & & $C 4$ & $C 5$ & C6 & & \\
\hline 1 & 8 & 6 & HA & 67 & $\mathrm{CS}$ & $\mathrm{S}$ & $\mathrm{S}$ & $\mathrm{S}$ & $\mathrm{S}$ & $\mathrm{S}$ & - & \\
\hline 2 & 12 & 7 & HA & 49 & $\mathrm{CS}$ & & & $\mathbf{N}$ & $\mathbf{N}$ & $\mathbf{N}$ & & \\
\hline 3 & 7 & 8 & HA & 49 & OPLL & $\mathrm{S}$ & $\mathrm{S}$ & $\mathrm{S}$ & $\mathrm{S}$ & $\mathrm{S}$ & $\mathrm{S}$ & $\mathrm{S}$ \\
\hline 4 & 1 & 8 & HA & 64 & OPLL & $\mathrm{S}$ & - & - & - & $\mathrm{S}$ & - & - \\
\hline 5 & 1 & 10 & HA & 66 & OPLL & $\mathrm{S}$ & $\mathrm{S}$ & $\mathbf{N}$ & $\mathbf{N}$ & - & $\mathrm{S}$ & $\mathrm{S}$ \\
\hline 6 & 2 & 10 & HA & 77 & OPLL & $\mathrm{S}$ & $\mathrm{S}$ & $\mathrm{S}$ & $\mathrm{S}$ & $\mathrm{S}$ & $\mathrm{S}$ & \\
\hline 7 & 2 & 11 & HA & 44 & $\mathrm{CS}$ & & $\mathrm{S}$ & $\mathrm{S}$ & $\mathbf{N}$ & $\mathrm{S}$ & $\mathrm{S}$ & \\
\hline 8 & 6 & 13 & HA & 46 & CS & S & $\mathrm{N}$ & $\mathrm{S}$ & $\mathrm{S}$ & $\mathrm{S}$ & $\mathrm{S}$ & \\
\hline 9 & 2 & 13 & HA & 48 & OPLL & & - & - & - & - & $\mathrm{S}$ & $\mathrm{S}$ \\
\hline 10 & 2 & 21 & $\mathrm{HA}$ & 63 & OPLL & $\mathrm{S}$ & $\mathrm{S}$ & $\mathrm{S}$ & $\mathrm{S}$ & $\mathrm{S}$ & & \\
\hline 11 & 10 & 30 & HA & 68 & $\mathrm{CS}$ & & $\mathrm{N}$ & - & - & $\mathrm{S}$ & $\mathrm{L}$ & \\
\hline 12 & 4 & 32 & $\mathrm{HA}$ & 63 & CS & & $\mathbf{N}$ & $\mathrm{S}$ & $\mathrm{S}$ & $\mathrm{S}$ & $\mathrm{S}$ & \\
\hline 13 & 2 & 52 & HA & 63 & $\mathrm{CS}$ & & $\mathrm{S}$ & $\mathrm{S}$ & $\mathrm{S}$ & $\mathrm{N}$ & $\mathrm{N}$ & \\
\hline 14 & 1 & 10 & $\mathrm{ABG}$ & 66 & OPLL & - & - & - & - & $\mathrm{N}$ & - & - \\
\hline 15 & 4 & 12 & $\mathrm{ABG}$ & 68 & CS & & $\mathbf{N}$ & $\mathbf{N}$ & $\mathbf{N}$ & $\mathbf{N}$ & $\mathrm{N}$ & \\
\hline 16 & 4 & 21 & $\mathrm{ABG}$ & 64 & OPLL & $\mathbf{N}$ & $\mathrm{N}$ & $\mathbf{N}$ & $\mathbf{N}$ & $\mathrm{N}$ & $\mathrm{N}$ & \\
\hline 17 & 10 & 30 & $\mathrm{ABG}$ & 68 & CS & & - & $\mathrm{S}$ & $\mathrm{L}$ & - & - & \\
\hline 18 & 2 & 44 & $\mathrm{ABG}$ & 51 & OPLL & - & $\mathbf{S}$ & - & - & $\mathbf{N}$ & $\mathrm{N}$ & \\
\hline 19 & 4 & 85 & $\mathrm{ABG}$ & 52 & CS & & $\mathrm{N}$ & $\mathrm{N}$ & $\mathbf{N}$ & $\mathrm{N}$ & $\mathrm{N}$ & \\
\hline
\end{tabular}

First CT: period between operation and the time the first CT image was taken. Second CT: period between operation and the time the second CT was taken. HA: hydroxyapatite; ABG: auto bone graft; CS: cervical spondylotic myelopathy; OPLL: myelopathy due to ossification of the posterior longitudinal ligament; S: short; N: no change; L: long (See text for the criteria); -: unmeasurable because of unclear CT images 
Chi-square test was used to examine the results statistically and a significant standard was defined as more than $99 \%$.

\section{Results}

Sixty spinous processes in the HA group and 22 in the ABG group were compared (Table 1). The short spinous process (Figure 2) was observed in $80 \%$ of the former and in $9 \%$ of the latter, the incidence of shortening thus being significantly higher $(P<0.01)$ in the HA group (Table 2).

There was no significant difference between the incidence of the short spinous process and patient's age at operation, the type of disease, the surgical level, or the period between the operation and the time when the second CT image was taken (Table 3).

\section{Discussion}

As it is difficult to take a CT image at two different times in an identical plane, credibility in the methodology of this study must be carefully evaluated. However, as there were only a few instances of shortening or lengthening of the spinous process in the

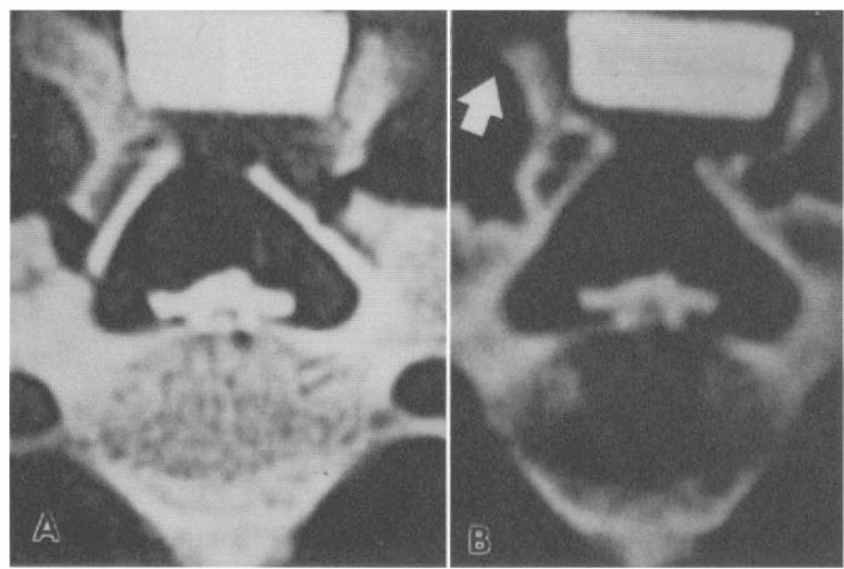

Figure $2 \mathrm{CT}$ images of $\mathrm{C} 3$ of patient number 5 with cervical myelopathy due to OPLL. Note shortening of the spinous process (arrow) 10 months postoperatively (B) in comparison with that 1 week postoperatively (A)

Table 2 Relationship between the type of spacer and the incidence of a short spinous process after expansive laminoplasty

\begin{tabular}{|c|c|c|c|}
\hline Change $\dagger$ & No. of $s t$ & us process & \\
\hline in spinous process & HA group & $A B G$ group & \\
\hline Short & $48(80 \%)$ & $2 \quad(9 \%)$ & $P<0.01^{*}$ \\
\hline No change & $11(18 \%)$ & $19(86 \%)$ & \\
\hline Long & $1 \quad(2 \%)$ & $1 \quad(5 \%)$ & \\
\hline Total & 60 & 22 & \\
\hline
\end{tabular}

*: HA group versus $\mathrm{ABG}$ group, chi-square test; $\dagger$ : see text for the criteria; For other abbreviation see Table 1
Table 3 Relationship of the period between operation and the time that the second CT was taken, and the incidence of a short spinous process

\begin{tabular}{lcc}
\hline & No. of spinous process & (short/evaluated) \\
Period & HA group & ABroup \\
\hline 6 months-1 year & $28 / 34(82 \%)$ & $0 / 1 \quad(0 \%)$ \\
1 year-2 years & $12 / 13(92 \%)$ & $0 / 11(0 \%)$ \\
2 years - & $8 / 13(61 \%)$ & $2 / 10(20 \%)$ \\
& NS $\ddagger$ & NS $\ddagger$ \\
\hline
\end{tabular}

$\ddagger$ : among three groups according to follow-up period, chisquare test; NS: not significant; For other abbreviations see Table 1

ABG group, the method used was seen to have an adequate degree of accuracy to prove significant shortening of the spinous process.

This study showed that the short spinous process was more common in patients where $\mathrm{HA}$ was used than in those using ABG. Neither age, the type of disease nor the surgical level had any significant influence on the incidence of the short spinous process. As this process was already observed in $82 \%$ of the patients 6 months to 1 year after the operation, the phenomenon was thought to occur early in the postoperative period. Reports of experiments with animals state that newly formed bone was detected in the pores of the HA inserted into bone medulla ${ }^{10}$ or placed on the periosteum ${ }^{11}$ within several weeks, and HA is thus thought to exhibit bone conductivity as long as it comes into contact with bone tissue. Although the reason for the shortening of the spinous process observed in a significant number of HA cases in this study is not yet clear, the contact between the split spinous processes and the HA spacer may not have been adequate for HA to demonstrate bone conductivity, because of the small contact area and/or the motion of the cervical spine.

The use of HA has the advantage of being less invasive than $\mathrm{ABG}$, however, it may jeopardize the biomechanical function of the nucheal muscles by reducing the original length of the spinous process. Further studies are required to determine the actual influence of this process on the biomechanical function of the cervical spine.

\section{References}

1 Crandall P, Gregorius F. Long-term follow-up of cervical spondylotic myelopathy. Spine 1977; 2: 139-146.

2 Yonenobu $\mathrm{K}$ et al. Choice of surgical treatment for multisegmental cervical spondylotic myelopathy. Spine 1985; 10: $710-$ 716.

3 Kurokawa T. Double door laminoplasty by longitudinal splitting of the spinous process. Bessatsu Seikeigeka 1982; 2: 234-240 (in Japanese)

4 Hoshino Y et al. The double door laminoplasty by longitudinal splitting of spinous process. Sekitsui Sekizui 1992; 3: 115-121 (in Japanese). 
5 Ohnishi I, Kurokawa T, Hirabayashi S. Laminoplasty on cervical myelopathy due to athetoid cerebral palsy. Rinsho Seikeigeka 1989; 24: 505 - 510 (in Japanese).

6 Ito $\mathrm{J}$ et al. Laminoplasty by splitting the spinous process using hydroxyapatite as an intra-spinous spacer. Sekitsui Sekizui 1990; 3: $556-562$ (in Japanese).

7 Hoshino Y, Kurosawa H. The application of hydroxyapatite spacer to double open-door laminoplasty in cases of cervical myelopathy. Kanto Seisaishi 1982; 23: 66-69 (in Japanese).

8 Kokubun $\mathrm{S}$ et al. Kurokawa cervical laminoplasty using hydroxyapatite spinous process spacer. Proceedings of the 5th Annual Meeting of the Japan Spine Research Society 1991; 233. (Abstract) (in Japanese).
9 Hoshi $\mathrm{K}$ et al. Bone reaction around spinous spacer in double door laminoplasty by longitudinal splitting of the spinous processes-hydroxyapatite vs. bone auto graft. Proceedings of the 8th Annual Meeting of the Japan Spine Research Society 1994; 214. (Abstract) (in Japanese).

10 Aoki H, Kato K, Tabata T. Osteocompatability of apatite ceramics in mandible. Rep Inst Med Dent Eng 1977; 11: 33-35.

11 Nemoto $S$ et al. Histological observation of the tibial periosteum reaction to porous hydroxyapatite sintered body in rats. Seikeisaigaigeka 1987; 30: 1421 - 1424 (in Japanese). 